\title{
Two Cases of Neuroendocrine Tumor of the Testis
}

\author{
Ahmad Alaqqad ${ }^{1 *}$, kholoud Alqasem², Niveen Abdullah ${ }^{3}$, Ali Al-daghmin4 \\ ${ }^{1}$ Surgery department, King Hussein cancer Center, Amman Jordan \\ ${ }^{2}$ Medicine department, King Hussein cancer center Amman, Jordan \\ ${ }^{3}$ Pathology department, King Hussein cancer center, Amman Jordan
}

Received: June 16, 2016; Accepted: June 18, 2016; Published: June 25, 2016

*Corresponding author: Ali Al-daghmin, King Hussein Cancer Center, department of surgery, Queen Rania Al-Abdullah St. Jubaiha, Amman, Jordan, Shmeesani, Amman 11194, P.o box 941900, Jordan,Tel: +962796666490; Fax: (+962-6) 5353 001; E-mail: a_daghamin@hotmail.com

\begin{abstract}
Testicular cancer is uncommon with an incidence of about 5.6 per 100,000 men per year among the U.S. population. Neuroendocrine tumor of the testis accounts for less than $1 \%$ of all testicular tumors. In this paper we present two cases of primary neuroendocrine tumor of the testis, The first one is a 17 year old male patient who presented with testicular pain and was found to have well differentiated histopathologic features (carcinoid tumor). The second case was a 40-year-old male patient who presented with painless scrotal swelling and was found to have moderately differentiated histopathologic features (atypical carcinoid)
\end{abstract}

Keywords: Carcinoid; Testicular carcinoid; Testicular neuroendocrine tumor; Testis

\section{Introduction}

Neuroendocrine tumors also called carcinoid tumors arise from enterochromaffin cells, which are found throughout the body. They commonly arise from the intestinal and respiratory epithelium (65\% and $25 \%$, respectively). For that, one should exclude the possibility of metastatic tumor to testis before labeling the case as a primary testicular carcinoid tumor. [1] In 1930, Cope described the first case of metastatic carcinoid tumor of the small bowel to the testis,[2] and Simon et al. Reported the first case of primary testicular carcinoid, since then, more than 60 carcinoid tumors have been reported. [3] The usual presentation of testicular carcinoid tumor is a painless mass or to be accidentally discovered during ultrasound for another reason. [4]

\section{Cases Reports}

\section{Case 1}

A 17-year-old male patient, not known to have previous illnesses, presented with right testicular pain associated with gradual swelling. He denied any weight loss, trauma, hematuria or systemic symptoms. Upon admission his Hemoglobin was 14.5 $\mathrm{g} / \mathrm{dl}$; white blood cell count $8.410^{\prime} 3 / \mu \mathrm{L}$, and creatinine $0.9 \mathrm{mg} /$ $\mathrm{dl}$, Electrolytes and liver function test values were within normal. He had a body mass index of $18 \mathrm{~kg} / \mathrm{m} 2$. He underwent radical orchiectomy, which microscopically revealed a well differentiated neuroendocrine tumor confined to the testis and epididymis with no lymph vascular invasion. No other teratomatous elements or germ cell components were identified. Immunohistochemistry showed the tumor cells to be positive for chromogranin and CK(MNF) while negative for inhibit, calretinin and melan-A. Ki67 proliferative index is $3-4 \%$ (Figure 1). An extra testicular carcinoid tumor was ruled out and the tumor was staged as pT1NxMx. After two years of follow up with cross sectional imaging and tumor markers including chromogranin $\mathrm{A}$ and 5-Hydroxyindoleacetic Acid, no recurrence has been documented and the patient is doing well.

\section{Case 2}

A 40-year-old male patient, not known to have previous illnesses, who presented with a progressive, painless left testicular swelling, he denied any weight loss, trauma, hematuria or systemic symptoms. On physical examination a hard mass was palpable on the left testis. Upon admission his hemoglobin was $13.6 \mathrm{~g} / \mathrm{dl}$, white blood cell count 7.4 10'3/ $\mu \mathrm{L}$, and Creatinine 1.0, electrolytes and liver function test values were within normal range. He had a body mass index of $26 \mathrm{~kg} / \mathrm{m} 2$. He had ultrasound imaging which showed a mass of about $5 \mathrm{~cm}$ associated with hydrocele (figure 2,3).

The patient underwent radical orchiectomy, which revealed

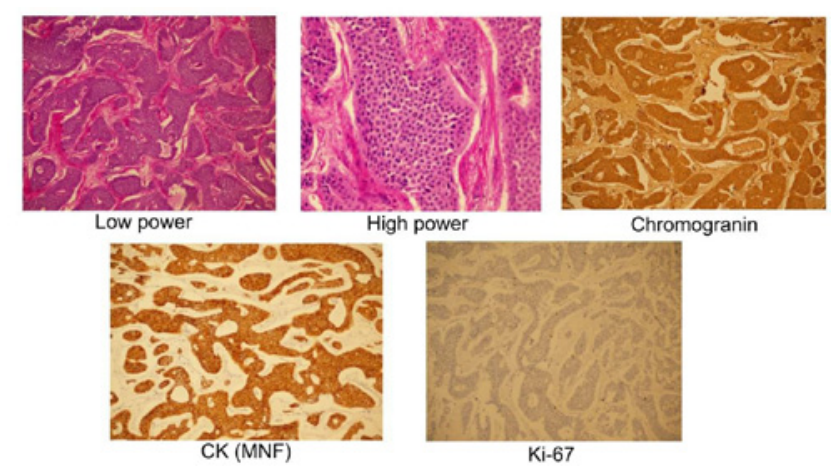

Figure 1: The histopathologic findings of case 1. 
grossly a mass measuring $5 \mathrm{X} 4 \mathrm{~cm}$ and a hydrocele composed of hemorrhagic fluid. Microscopically, the mass was confined to the testis and epididymis with no lymph vascular invasion. The presence of $5 \mathrm{MF} / 10 \mathrm{HPF}$ and a Ki-67 proliferative index of $15 \%$ indicate that this is an intermediate grade neuroendocrine neoplasm (atypical carcinoid). The tumor cells are positive for CD56 and synaptophysin. They are negative for SALL-4 and CD30 (see figure 4). The tumor was staged as pT1NxMx.

The patient is planned to be followed up on active surveillance with cross-sectional imaging and tumor markers including chromogranin A and 5-Hydroxyindoleacetic Acid which.

\section{Discussion}

Testicular cancer is uncommon with an incidence of about 5.6 per 100,000 men per year among the U.S. population [5]. Neuroendocrine tumor of the testis represents $1 \%$ of all testicular tumors [6]. The testicular carcinoid tumor can be primary, associated with teratoma or metastatic from another origin. Primary carcinoid tumor of the testis carries an excellent prognosis, $[7,8]$. The overall incidence of metastasis is about $11 \%$ [9] and they are thought to be as a differentiation of the pluripotential germ cell to argentaffinlike cells or the development of a simplified teratoma without other teratomatous elements. $[10,11]$. Although it should be the first concern to rule out that it is metastatic disease from another site, as the primary tumor cannot be distinguished from metastatic one usingonly the histopathologic findings. [12]. It also has been noted that the larger the tumor the more malignant it seems to be [12].

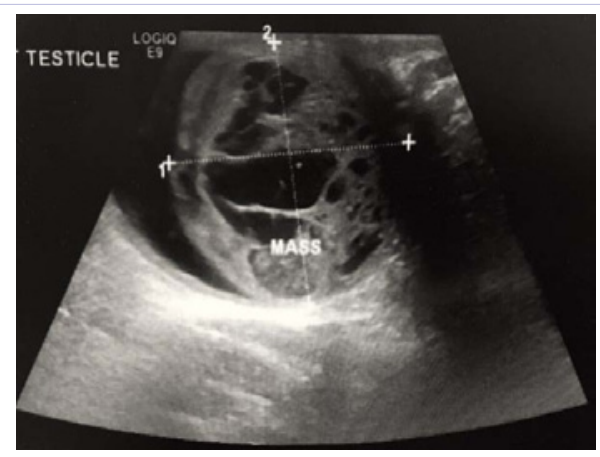

Figure 2: The Ultrasound showing the mass for case 2.

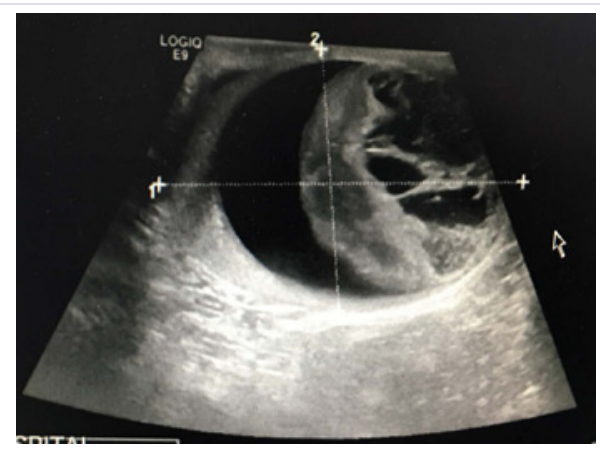

Figure 3: Ultrasound showing the mass and hydrocele for case 2.

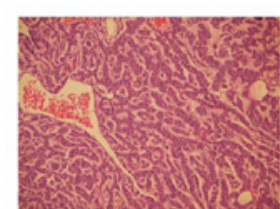

Low power

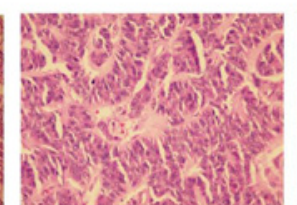

High power

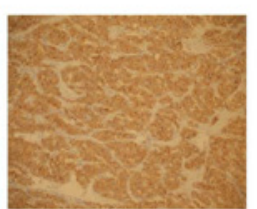

Synaptophysin
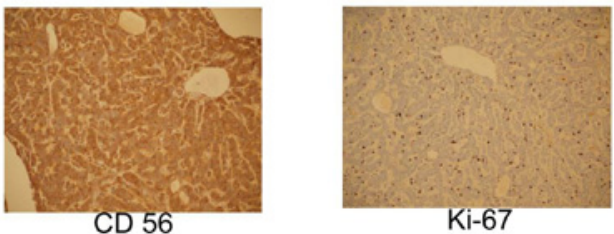

Ki-67

Figure 4: The histopathologic findings of case 2 .

According to the published cases, the right testis seems to have a higher chance of developing primary carcinoid of the testis $[8,9]$. Primary testicular carcinoid is difficult to diagnose preoperatively as the currently available imaging modalities unable to differentiate it from other testicular tumors such as germ cell tumors and it is a rare tumor that routine laboratory markers are not cost effective to be done [13]. The most common presentation of testicular carcinoid tumors is painless testicular swelling, nevertheless association with hydrocele and pain has been noted in some cases [6]. It is also known that metastatic testicular carcinoid tumor could present with carcinoid syndrome with symptoms of hot, red flushing of the face; severe and debilitating diarrhea; andasthma attacks. These symptoms are usually the result of substances secreted by the tumor [14].

\section{References}

1. Howlader N, Noone AM, Krapcho M, Garshell J, Miller D, Altekruse SF, Kosary CL, Yu M, Ruhl J, TatalovichZ, Mariotto A, Lewis DR, Chen HS, Feuer EJ, Cronin KA (eds). SEER Cancer Statistics Review, 1975-2012, National Cancer Institute. Bethesda, MD, based on November 2014 SEER data submission, posted to the SEER web site, 2015.

2. Ulbright TM, Amin MB, Young RH. Atlas of Tumor Pathology: Tumors of the Testis, Adnexa, Spermatic Cord, and Scrotum 1999. International Journal of Andrology. 2000;23(4):254.

3. Zuetenhorst JM, Taal. Metastatic carcinoid tumors: a clinical review. Oncologist. 2005;10(2):123-31.

4. Cope 2. Metastasis of an argentaffin carcinoma in the testicle. Clinical Details. B j Uro.1930;3:21268-72.

5. Harvey Kemble JVMA. Argentaffin carcinoma of the testicle. Br J Urol. 1968;40:580-4

6. Sandeep Singh Lubana, Navdeep Singh, Hon Cheung Chanand David Heimann. Primary Neuroendocrine Tumor (Carcinoid Tumor) of the Testis: A Case Report with Review of Literature. Am J Case Rep. 2015;16:328-332

7. Wang WP, Guo C, Berney DM, Ulbright TM, Hansel DE, Shen R, et al. Primary carcinoid tumors of the testis: a clinicopathologic study of 29 cases. Am J SurgPathol. 2010; 34(4):519-24.

8. Changli Lu, Zhang Zhang, Yong Jiang, Zhirong Yang, Qunpei Yang, Dianying Liao, et al. Primary pure carcinoid tumors of the testis: Clinicopathological and immunophenotypical characteristics of 11 cases. Oncol Lett. 2015;9(5):2017-2022. 
9. Hayashi T, Iida S, Taguchi J, Miyajima J, Matsuo M, Tomiyasu K, et al. Primary carcinoid of the testis associated with carcinoid syndrome. Int J Urol. 2001;8(9):522-4

10. Terhune DW, Manson AL, Jordon GH, Peterson N, Auman JR, MacDonald GR, et al. Pure primary testicular carcinoid: a case report and discussion. J Urol. 1988;139:132-133.

11. Petersen RO. Testis. In: Petersen RO (ed). Urologic Pathology. 2nd ed. Philadelphia, PA: JB Lippincott Co; 1992:429-525.

12.Zavala-Pompa A, Ro JY, el-Naggar A, Ordóñez NG, Amin MB, Pierce $\mathrm{PD}$, et al. Primary carcinoid tumor of testis.Immunohistochemical, ultrastructural, and DNA flow cytometric study of three cases with a review of the literature. Cancer. 1993;72(5):1726-32.

13. Sung Bin Park, MD, JeongKon Kim, MD, Kyoung-Sik Cho, MD Imaging Findings of a Primary Bilateral Testicular Carcinoid Tumor Associated With Carcinoid Syndrome. J Ultrasound Med 2006;25:413-416.

14. Kato N, Motoyama T, Kameda N, Hiruta N, Emura I, Hasegawa G, et al. Primary carcinoid tumor of the testis: Immunohistochemical, ultrastructural and FISH analysis with review of the literature. Pathol Int. 2003;53(10):680-5. 